Acta Hispanica (2020) Supplementum II: 387-394

\title{
LOS DESPLAZAMIENTOS HUMANOS Y LA IDENTIDAD CULTURAL
}

\author{
DOLORES MARTIN RODRÍGUEZ CORNER \\ Laboratório de Estudos sobre Etnicidade, Racismo e \\ Discriminação, USP
}

\begin{abstract}
Resumen: Los desplazamientos humanos ocurren desde tiempos remotos por cuestiones sociales, económicas o políticas que son las que impulsaron las salidas. Sin embargo, las migraciones en el mundo fueron intensificadas en el siglo XX. Estos traslados a nuevos y desconocidos contextos producen contrastes culturales. Además, la alteridad promueve la interacción de culturas en los hábitos cotidianos, provocando que el emigrante termine por convertirse en una persona híbrida. Al cruzar frontera el individuo empieza un proceso que objetiva su permanencia, pues su retorno no siempre le sería posible. En este momento las asociaciones regionales ejercen un papel imprescindible para esclarecer las raíces e identidades del inmigrante. Las manifestaciones culturales presentadas en sus fiestas, como la danza, la música y la gastronomía, presentes en la memoria, evocan el país de origen.
\end{abstract}

Palabras clave: cultura, hábitos, identidad, inmigración, memoria.

Abstract: Human displacement has occurred since ancient times, motivated by social, economic or political issues that led to migrations. However, these migrations were intensified in the 20th century. These transfers to new and unknown contexts produce cultural contrasts. In addition, alterity promotes the interaction of cultures in the daily life of the emigrant, and this mixture produces a hybrid person. By crossing borders, the individual begins a process that aims at his adaptation and permanence, since his return might become impossible. At this moment, the regional associations have an essential role in clarifying the origins of the immigrant. In their festivities, cultural manifestations like dance, music and gastronomy, are present in their memory and evoke their country of origin.

Keywords: Culture, Habits, Identity, Immigration, Memory.

\section{Introducción}

Los desplazamientos humanos ocurren desde tiempos remotos por cuestiones sociales, económicas o políticas que son las que impulsaron las salidas en búsqueda de un lugar de acogida, que les ofreciera un refugio. Muchos espontáneamente, mientras otros, por cuestiones que exige la emergencia, se ven obligados a hacerlo, como única salida posible para poder sobrevivir. La difícil decisión de emigrar, llevando sus parcas pertenencias en situación de incertidumbre, sin informaciones del país de destino, representa una actitud de coraje con rasgos muchas veces de aventura e ilusión delante los demás vecinos del pueblo. En este sentido, el retorno a su tierra significaría frustración y fracaso, como si la elección hubiera sido equivocada. 
La llamada primera ola inmigratoria, de inmigración europea hacia América, ocurrió a fines del siglo XIX e inicios del XX, organizada con el objetivo de suplir la falta de brazos para el trabajo en los cafetales. La emigración española era caracterizada como una inmigración familiar, que interesarían a los hacenderos propietarios de las fincas por la cantidad de hijos hombres, pues cada hijo sería contado como una azada para el trabajo del campo.

Después del término de la Guerra Civil Española, se inició la persecución del gobierno a los contrarios al régimen nacionalista, y este hecho causó la segunda ola inmigratoria de españoles a América, especialmente a Brasil. Como el uso del castellano fue establecido como el único idioma permitido en el territorio español, los demás idiomas regionales como el gallego, el vasco o catalán estaban prohibidos en las ciudades, en las escuelas y en el campo. Teniendo en cuenta esta situación, muchos necesitaban huir a cualquier destino con inmediatez, y formaron un grupo, en su mayoría estrictamente masculino, o sea, muchos hombres por no tener condiciones de trabajo se marchaban a destinos inciertos. Debido a la urgencia de salir en el primer barco que surgiese, buscando un abrigo seguro, por cuestiones políticas y gubernamentales, las circunstancias les impedían en retornar a su país por significar prisión o muerte.

Estos traslados a nuevos y desconocidos contextos producían contrastes culturales muy claros. Así, pues, la interacción que siempre ocurre en estas situaciones, al intercambiar costumbres y hábitos cotidianos, se los mezcla, resultando al final del proceso en una persona híbrida, que mantiene su cultura y agrega nuevos hábitos y costumbres del lugar de acogida. Al cruzar fronteras, el individuo empieza un proceso de adaptación a nuevos lugares que tiene como objetivo principal su permanencia, pues el retorno casi siempre sería posible. Este es el momento en el que el asociacionismo ejerce un papel imprescindible para esclarecer las identidades del inmigrante. Las manifestaciones culturales presentadas en sus fiestas, como la danza, la música y la gastronomía, presentes en la memoria, evocan el país de origen. "Y, por cierto, cada vez con mayor frecuencia vamos recurriendo a la memoria de los espacios para esclarecer cualquier duda sobre nuestras raíces e identidades" (Dembicz, 2000: 15-26).

En el caso de inmigraciones la dinámica y las particularidades de cada grupo, que incluyen la época, los motivos, el género, la edad, el destino, el país de origen, etc., se constituyen en variables que facilitarán o no la permanencia. Según Elías (1990), el concepto de civilización, hasta cierto punto, minimiza las diferencias culturales de los pueblos; enfatiza lo que es común en todos los seres humanos, y manifiesta la autoconfianza de pueblos cuyas fronteras e identidades nacionales fueron tan plenamente establecidas desde siglos. Sin embargo, destaca el autor: "las costumbres enraizadas deben ser comprendidas no apenas como algo negativo, como 'falta de civilización' o de 'conocimiento', sino como algo que atendía a las necesidades de estas personas y que les parecía importante y necesario para ellas exactamente de esa forma.” Al hacer un análisis de este largo proceso por el cual pasan los que dejaron sus países para vivir una nueva 
realidad, casi siempre muy distinta de la suya, pronto notarán los contrastes culturales de los dos mundos.

\begin{abstract}
Vivir entre dos mundos culturales significa adentrar diferentes juegos de espejo realizados por los demás. Esos reflejos pueden afectar tanto positiva como negativamente el sentimiento de capacidad y valoración del self, que, unido al proceso de reflexión y observación simultáneas de si mismo, son las bases de la formación identitaria (Ferreira et. al, 2010: 12).
\end{abstract}

Viviendo en un ambiente de alteridad, el inmigrante descubre "el otro" con valores y costumbres distintos, cotidianamente confrontados, a veces valorados por el otro y a veces no, lo que le llevará a cuestionarlos. En vista de esto, el que emigra se vuelve una persona dividida, en su país o en otro, y por consiguiente, por estar entre dos mundos, teniendo en cuenta que tendrá que adecuarse al nuevo, aunque no se olvida de sus hábitos y su cultura de origen.

\title{
2. El inmigrante y la identidad cultural
}

La identidad cultural es fijada en el momento del nacimiento, sea como parte de la naturaleza, impresa a través del parentesco y de la línea de los genes, sea constituida de nuestro "yo" más interior. Es impermeable a algo tan mundano, secular y superficial como el cambio temporario de nuestro local de residencia. La pobreza, o subdesarrollo, la falta de oportunidades -los legados del imperio en toda parte pueden forzar a las personas a emigrar, lo que causa el desparramar- la dispersión, aunque cada diseminación lleva consigo la promesa del retorno redentor (Hall, 2003: 28).

Además de sus pertenencias puestas en pocas maletas, el inmigrante se lleva un inmenso equipaje cultural intrínsecamente incorporado en sus acciones y hábitos, especialmente los alimentarios que le exigirán el retorno a sus costumbres. Hall destaca que "la cultura es la suma de las descripciones disponibles por las cuales las sociedades tienen sentido y reflejan sus experiencias comunes" (2003: 135). En la alteridad, en contacto con diferentes costumbres, el habitus de cada persona funciona como una matriz de percepción, orientación y de la apreciación de la acción que se realiza; a través de eso, el pasado sobrevive en el momento actual, mientras intenta subsistir en las acciones futuras. Bourdieu llamó este proceso de "interiorización de la exterioridad y de exteriorización de la interioridad."

Según afirma Tedesco “[...] el migrante se desplaza de un sitio a otro; desplaza sus ritos, tradiciones y valores, presionado a incorporarlos de otros, esa dupla identidad forma la figura sociocultural del extranjero" (2006: 42). Sin embargo, el emigrante aun viviendo el proceso de adaptación en otro país, con el encuentro de empleo y vivienda, 
Los desplazamientos humanos y la identidad cultural

o sea, una nueva vida que se le inicia, en otro contexto que junta diversas culturas distintas a la suya, va a realizar la desconstrucción y reconstrucción de su identidad. El inmigrante jamás saldrá de la condición de extranjero, ni en su país, ni en el país de recepción, tanto que los portugueses retornados a su país después de algunos años de vida en Brasil eran considerados allí "brasileños", esta marca los acompañará en ambos espacios incluso en su propia tierra por sus conterráneos. Desde entonces será un ser híbrido, sujeto a adaptaciones de sus costumbres y tradiciones.

El proceso migratorio causa transformaciones en la manera de pensar que traen con ellas nuevas costumbres, otras visiones de mundo. Sin embargo, el sentimiento de pertenencia se queda más arraigado en el inmigrante, o sea, la necesidad de mantener sus tradiciones, su cocina, ocio, tras la ruptura resulta muchas veces el deseo de probar los sabores, oír las canciones, incluso poder hablar su idioma en la compañía de sus conterráneos, reencontrando sus valores y su identidad. Sin embargo, como hay interacción de culturas distintas en el proceso inmigratorio, esto resulta en cambios tanto en la vida del inmigrante como en la de los demás de la convivencia.

De acuerdo con Hall:

La identidad plenamente unificada, completa, segura y coherente es una fantasía, y que, al revés de eso, mientras los sistemas de significados y representación cultural se multiplican, somos afrontados por una multiplicidad desconcertante y cambiante de identidades posibles, con las cuales podríamos identificarnos temporalmente (2000: 13).

En casi todos los países de América, los inmigrantes buscaron juntarse, unirse organizándose en asociaciones o en Sociedades de Socorros Mutuos, como un medio de obtener apoyo, repatriación en el caso de fallecimiento del jefe de la familia y, sobre todo, mantener la cultura e identidad en sus encuentros. Por ejemplo, en São Paulo en el año 1898 los inmigrantes organizaron la Sociedad Hispano-Brasileña de Socorros Mutuos que todavía sigue activa hoy bajo el nombre de Casa de España.

Con la llegada de nuevos grupos regionales fueron surgiendo los centros como el gallego, valenciano, vasco, andaluz, asturiano y catalán, entre otros, los cuales promueven eventos y encuentros para que se sientan pertenecientes a su cultura. Las manifestaciones culturales presentadas en sus fiestas, como la danza, la música y la gastronomía, presentes en la memoria, evocan el país o la región de origen.

Estos centros existentes en los países de acogida permanecen como un guardián de la cultura de su tierra, como verdaderos territorios del país o región. Así, en los momentos del aislamiento de la cultura propia, ellos ejercen un papel imprescindible para mantener las raíces e identidades del inmigrante. Además, ellos permiten compartir las costumbres, el idioma, los símbolos, las representaciones y los sabores de su cocina en platos presentes en todos los eventos, preparados cariñosamente por las manos femeninas de las inmigrantes. 
[...] buscaban la afirmación de la identidad cultural - sobre todo en lo que se refiere a la manutención de la lengua en un país de idioma hablado diferente, y además todo tipo de manifestaciones, tanto folclóricas, como gastronómicas, expresadas en las romerías, festivales, y banquetes, con la difusión de valores e información (González, 2008: 365-387).

Muchas entrevistas realizadas para estudios académicos demuestran que el grupo de los inmigrantes españoles en São Paulo mantenían su idioma, con acento español como forma de resistencia en aceptar el uso de la lengua portuguesa. Es posible encontrar por los barrios de inmigrantes, aunque haya pasado tanto tiempo, a veces más de sesenta años desde su llegada, españoles que aún mantienen su acento regional, y el uso de su lengua en la comunicación con los brasileños o con compatriotas.

Haciendo un análisis sobre este grupo de inmigrantes, Klein resalta que lo que impresiona es la rapidez con la que los españoles se integraron a la vida en la sociedad, con el patrón de vida que alcanzaron en el país, llegando a punto de desparramarse por la ciudad, no constituyendo un barrio, ni siquiera una calle que los representara (1989: 457-476). Este hecho fue destacado por otros historiadores, como González refiriéndose a una rápida adaptación a la cultura local: “[...] a pesar de la 'irrenunciabilidad'1 que tienen de la identidad española, se sienten de alguna manera identificados con el país, sin que esto suponga ningún conflicto personal" (2008: 35).

En parte, se puede acreditar a la semejanza entre las dos culturas: la española y la portuguesa (de los colonizadores), ambas ibéricas, por la facilidad con que este grupo de inmigrantes, en su mayoría, se siente perfectamente adaptado. Además, ellos se refieren al acogimiento de la población local a los mismos, como uno de los factores que causaron su rápida adaptación en perfecta convivencia. Pasados muchos años de permanencia en Brasil donde constituyeron su familia, donde viven sus descendientes, aunque dediquen un cariño especial por su región de origen, como Galicia, Andalucía, Valencia o Asturias, al visitarla la mayoría siente que no volvería a vivir en su tierra.

El país que permaneció en la memoria sufrió cambios significativos causados por el tiempo, donde ni el ambiente ni la vecindad corresponde a lo dejado. Entre algunos inmigrantes entrevistados la mayoría declaró que nunca podría volver a vivir en España, pues su familia, sus descendientes se encontraban en Brasil y no querrían separarse de ellos.

Nostalgia no es el mal del retorno, pues una vez realizado se descubre que no es la solución: es verdad que no existe un retorno al idéntico. Si se puede volver al punto de partida, el espacio se sirve al ir y venir, pero de otro lado, no se puede volver al tiempo de la partida, volverse nuevamente a lo que se era en aquel momento, ni

\footnotetext{
${ }^{1}$ Término que significa la idea de no renunciar a su identidad española de origen.
} 
Los desplazamientos humanos y la identidad cultural

reencontrarse a la misma situación, a los lugares y a las personas que se quedaron, tal cual los dejó (Sayad, 1998: 11).

El inmigrante, al fijarse en otro país después de muchos años, incorporará nuevas costumbres, nuevas formas de alimentación, las cuales ya estarán incorporadas en su modo de vivir. Por si acaso ocurriera un retorno al país de origen pasado medio siglo, esto significaría una nueva emigración a ellos, pues ya cambiaron sus hábitos y costumbres por convivir en otra cultura distinta de la suya, ahora desarraigados de su tierra, de su propia gente.

En la historia de España especialmente País Vasco es el que explica muy bien la cuestión identitaria. La industrialización en la ciudad de Bilbao, Vizcaya, el gran desarrollo atrajo para sus industrias trabajadores de diversas regiones españolas y hasta de otros países. En este caso, con la llegada de trabajadores extranjeros, los ciudadanos locales se sintieron amenazados y pasaron a preocuparse por el resguardo de sus tradiciones, por saber que los que emigran llevan con ellos sus hábitos y su cultura. Así, volvieron a sus raíces y a sus costumbres.

La llegada masiva de inmigrantes, ajenos a los imperativos tradicionales de «ser vasco», en un momento de profunda crisis de identidad, aumentara el conflicto iniciado a fines del siglo XIX mientras alimentó de forma especialmente virulenta el sentimiento de amenaza de la propia identidad (Fernández de Valderrama, 1994: 36).

Los inmigrantes que fueron para trabajar en las industrias estaban mejor preparados que los vascos para el trabajo. Incluso el milenario idioma vasco, el euskera, hablado en esta región, era desconocido para los que llegaban para trabajar que, por no poder utilizarlo en la comunicación, empleaban el castellano. Esa realidad produjo un impacto tan grande que los vascos empezaron a luchar por la vuelta de los foros regionales, de la tradición y de las costumbres milenarias, rechazando la influencia española que llegó con los emigrantes, la cual era considerada nefasta.

Según Solozábal la presencia del "otro" llevó a reflexionar sobre la situación y destino como pueblo vasco, en un contexto multicultural, y sobre las personas extranjeras que irían impregnando sus costumbres, lo que hizo que volvieran a sus tradiciones y prácticas, temiendo su pérdida (1979: 15). En primer lugar, hubo un recrudecimiento de las prácticas culturales, por sentir la necesidad de volver a su propia cultura, valorándola aún más. " [...] en la inmigración, el "yo" se abre en perspectiva y se lanza en el futuro de un tiempo alternativo, experiencia esta que implica vivencias de rupturas y exige procesamientos y elaboraciones críticas de la subjetividad" (Ferreira, 2010: 15).

Según Hall la identidad cultural está siendo formada siempre en un proceso continuo que se va cambiando: "La identidad no debe ser vista como algo fijo e inmutable, sino como algo que se construye a lo largo de la vida, y que va cambiando según el contexto en el cual la persona está inserida" (2003: 28). Entre las diferentes formas de memoria 
colectiva, una de las más persistentes es la memoria culinaria, con su variedad de sabores, aromas y colores que resisten al impacto del tiempo y hasta mismo al desarraigo cultural y geográfico. "La culinaria representa un amplio arsenal de identidades que no se diluyen al contacto con otras personas, en la convivencia multicultural que resiste a los efectos pasteurizadores de la globalización” (Heck - Belluzzo, 1999: 14). Es el último hábito que es abandonado en el caso de inmigración.

Según Lèvi-Strauss: “Así se podrá esperar descubrir para cada caso particular, de qué modo la cocina de una sociedad es lenguaje por la cual ella traduce inconscientemente a su estructura" (2000: 218).

\section{Consideraciones finales}

La cuestión identitaria se evidencia en casos de emigración, por la alteridad, por las experiencias culturales vividas, las prácticas, los hábitos que se van cambiando a lo largo de la vida, sean los alimentarios, los personales de su cotidiano y de su vida. Es evidente que el hecho de dejar su país y empezar una nueva vida, con sus hábitos mezclándose con los de la sociedad receptora, promueven una interacción en la que ambas culturas se impregnan una de la otra resultando en una persona híbrida, según el contexto encontrado. Es inevitable que eso no ocurra, en dichos ambientes, pues siempre habrá interacción entre las culturas que se encuentran.

Sin embargo, por más que el tiempo pase, los valores y costumbres estarán vivos y presentes en su vida, en sus actitudes y hábitos. Los estudios culturales nos permiten un análisis de los símbolos de cada grupo emigrante, y la importancia de su cultura. Se destacan los hábitos alimentarios considerados los últimos a ser abandonados, en el caso de emigración, pues forman parte del habitus de las personas y estarán presentes en la memoria afectiva. En sus casas, al preparar la alimentación, los españoles inmigrantes siempre van buscando el uso de los ingredientes indispensables de su cultura, como ajos fritos en el aceite de olivas, no solo por el olor característico de su cocina, sino por el sabor inconfundible.

En las fiestas regionales los platos más emblemáticos del país de origen son los servidos en el momento cumbre de estas, el momento más esperado por todos, que los hacen recordar de los sabores de la memoria para que sean revividos. Los momentos que estas fiestas propician al inmigrante son inolvidables por el contacto posible con sus pares cuando se permite la práctica del idioma, las músicas que les traen a la memoria el pueblo, la familia, el entorno dejado, y además por disfrutar del gusto de su cocina étnica preparada por señoras inmigrantes con sus técnicas no reveladas.

El inmigrante no se integra siempre en su centro regional, sea el vasco, gallego, andaluz, valenciano u otro. Muchas veces por vivir distante de estos centros, como es el caso de quien vive en la ciudad de São Paulo que no permite desplazamientos largos, por el tráfico y por la distancia. Otros no tienen tiempo libre por el trabajo intenso que no les permite disfrutar del ocio y de este contacto que les aproxima a sus conterráneos. 
Los desplazamientos humanos y la identidad cultural

Así, la trayectoria de cada persona, la familia que constituyó en el país de recepción, el hecho de ser hombre o mujer, implican mayor o menor posibilidades de mantener su cultura, sea a través del idioma o de la cocina, la cual permite a las mujeres el preparo de la comida empíricamente recibida de su familia y transmitida a los demás. Por más distante que esté, por más alejado se quede de sus orígenes, al escuchar una música, al oír el idioma hablado, al probar un sabor que le recuerde su origen, el sentimiento de pertenencia siempre estará presente. Habrá siempre un rasgo muy fuerte de su cultura impregnado en su mente y en sus actitudes, aunque lejos del origen de nacimiento.

\section{Referencias bibliográficas}

Dembicz, Andrzej (2000). Espacio - Memoria - Identidad. En: Toribio Brittes Lemos, Maria Teresa - Moraes, Nilson (coords.). Memória e Identidade. Rio de Janeiro: 7 letras.

Elias, Norbert (1990). O processo civilizador - Uma história dos Costumes. Vol. I. Rio de Janeiro: Ed. Jorge Zahar.

Fernandez de Valderrama, Cristina Blanco (1994). Inmigración e identidad colectiva. Reflexión sobre la identidad en el País V asco. Leioia: Universidad del País Vasco.

Pacelli Ferreira, Ademir - Vainer, Carlos B. - Povoa Neto, Helion - Oliveira Santos, Miriam de (coords.) (2010). A Experiência Migrante. Entre deslocamentos e Reconstrucõos. Rio de Janeiro: Ed. Garamond.

González-Martínez, Elda (2008). Tres inmigrantes, cuatro centros, un periódico... las asociaciones españolas en Brasil. En: Blanco-Rodríguez, Juan André (ed.). El asociacionismo en la emigración española a América. Zamora: UNED. 365-387.

Hall, Stuart (2003). Da Diáspora: Identidades e Mediações Culturais. Belo Horizonte: UFMG. Hall, Stuart (2000). A identidade cultural na Pós-Modernidade. $4^{\mathrm{a}}$ ed. Rio de Janeiro: DP \& A. Heck, Marina - Belluzzo, Rosa (1999). Cozinha dos Imigrantes. Memórias \& Receitas. São Paulo: Ed. Melhoramentos.

Klein, Herbert (1989). A Integração Social e Econômica dos imigrantes espanhóis no Brasil. Estudos Econômicos, 19/13. 457-476.

Sayad, Abdelmalek (1998) A Imigração ou os Paradoxos da Alteridade. São Paulo: Editora da Universidade de São Paulo.

Solozábal Echavarría, Juan José (1979). El primer nacionalismo vasco. Industrialismo y conciencia nacional. San Sebastián: Haranburu.

Tedesco, João Carlos (2006). Imigração e Integração Cultural: Interfaces. Santa Cruz do Sul: EDUNISC. 